\title{
Design and simulation of cascaded H-bridge multilevel inverter with energy storage
}

\author{
Tan Chee Ting ${ }^{1}$, Zulhani Rasin², Chan Sia Ching ${ }^{3}$ \\ ${ }^{1,2}$ Faculty of Electrical Engineering, Universiti Teknikal Malaysia Melaka, Hang Tuah Jaya, Melaka, Malaysia \\ ${ }^{3}$ Wah Loon Plant \& Instrumentation Pte Ltd, Tagore Drive, Wah Loon Building, Singapore
}

\begin{abstract}
Article Info
Article history:

Received May 28, 2021

Revised Jul 21, 2021

Accepted Aug 4, 2021

\section{Keywords:}

Bidirectional converter Cascaded H-bridge inverter Energy storage Multilevel inverter Stand-alone PV system

ABSTRACT

Stand-alone power system provides a solution for the user in rural areas that are disconnected from the utility grid which requires power electronics device for the power conversion. This work proposes a design of 5-level cascaded H-bridge inverter with energy storage to realize DC-AC power conversion for such system. The DC-DC bidirectional converter is designed to control the charging and discharging of current into/from the battery during the buck and boost mode of operation. At the DC side, dual-loop control strategy using PI controllers is designed to control the current and voltage. The inner loop current controller controls the recharging/discharging of current for the battery, while the outer voltage controller controls the DC link voltage at $200 \mathrm{~V}$ for each of the H-bridge unit. At the AC side, multiple feedback loop control strategy regulates the inverter output voltage at 240 Vrms under various load change. The modelling and design of the system is implemented under Matlab Simulink environment. From the results, the battery storage unit works well with the DC link voltage to achieve a balance power transfer within the system between the PV source, load and battery storage under variation of PV power and loading condition.
\end{abstract}

This is an open access article under the CC BY-SA license.

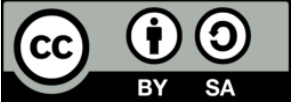

\section{Corresponding Author:}

Zulhani Rasin

Faculty of Electrical Engineering

Universiti Teknikal Malaysia Melaka

Hang Tuah Jaya, 76100 Durian Tunggal, Melaka, Malaysia

Email: zulhani@utem.edu.my

\section{INTRODUCTION}

The stand-alone power system is a solution for the user in some rural areas that are disconnected from the utility grid. Solar system harvests electrical energy from sun irradiance and provides power to appliances. The system typically consists of solar photovoltaic, inverter and the energy storage unit. The power source is from the solar photovoltaic panels which produce DC power to the system. As the power supply from the photovoltaic are very unstable due to dependency on the irradiance and temperature, the battery must be able to support the load when the photovoltaic unable to provide sufficient electrical power. In reverse, the photovoltaic must be able to charge the battery when there is abundant power available. In a standalone power system, the inverter requires a stable DC power from the photovoltaic source to convert direct current $(\mathrm{DC})$ to alternating current $(\mathrm{AC})$ power.

The use of bidirectional DC-DC converter (BDC) for integrating the DC source to the AC system has been investigated previously, for instance in [1]-[4] for various application such as renewable energy system, electrical drive and power supply. Apart from regulating the voltage levels, the main attraction is on its ability and flexibility to realize a bidirectional power between the source and load in the system. In 
particular for interfacing the energy storage unit to the inverter, various control methods for controlling the voltage and current has been explored such as in [5]-[8] with the objectives to achieve better response of DC link voltage regulation, low voltage and current stress, good ripple performance as well as improving the life cycle of the energy storage.

The bidirectional converters in general can divided into two types, isolated and non-isolated type. The application of non-isolated kind of topology topology such as the widely used buck/boost converter [9] and the more advance high step-up three port DC-DC converter [10] able to transfer power without magnetic isolation. The model and method are simpler and cheaper than the isolated topology. Meanwhile, isolated bidirectional converter converts DC voltage to AC voltages which passes through high frequency transformer and then rectified to DC waveform. Therefore, isolated converter has higher step up voltage gain ratio as shown in [11] with galvanic isolation. The gain of the converter is added with additional degree of freedom causes it able to perform with wide ranges requirement of input voltage and load regulation [12]. The disadvantages of isolated bidirectional converter are the magnetic interference and higher weight compared to non-isolated bidirectional converter.

The control methods for bidirectional converter are also divided into two main categories which are the general control schemes and the switching strategies. The control methods depend on the control problem and topology of the bidirectional converter. Control method for non-isolated bidirectional converter is simple where there is no transformer implementation. Isolated topology provides advantages of easy realization of soft switching control when isolation between load and sources is needed. This is mainly used in high power application, where it controls the energy flow and protect the operators and equipments from damage and danger.

Apart from the conventional two-level inverter, the application of multilevel inverter (MLI) in PV system has gained a huge interest due to its many advantages, such as a lower rating component usability, better quality of output waveform and higher efficiency [13]. Several types of multilevel inverter are available and among them, the cascaded H-bridge MLI with much simpler topology has been widely discussed and applied such as in the optimization of component number and voltage supply [14], utilization of multicarrier modulation technique [15] and modified phase-shift PWM scheme [16], as well as application in standalone PV inverter system [17]. Compared with other types of MLI, it requires the lowest number of semiconductor devices, and its modularity character contributes to simplicity of control.

In stand-alone PV application, one of the important aspects is on the control of the output voltage for feeding the load. The objectives are to produce a pure sinusoidal output voltage with low harmonic distortion and rapid dynamic response. The change in loading condition must be constantly monitored to prevent overvoltage condition. Among the available control techniques, the dead-beat control technique can produce a low THD value and a quick transient response to the inverter [18]. The feedback signal of the fundamental of rms value of the output voltage is compared with the reference voltage and the difference between the two signals are sent to the PI controller to get the appropriate modulation index. Although this control technique can provide the fastest dynamic response to the output voltage, it is sensitive to the parameter variation of the filter modeling [19]. The multiple feedback loop control technique such as in [20]-[22] provides a good dynamic response to a low total harmonic distortion (THD) output voltage. The multiple feedback loop control has two control feedback signals, where the internal loop is the filter capacitor's current control and the external is the output voltage control loop. This technique improves the THD of the output voltage and current which is near to a constant sinusoidal output load voltage. Thus, this control technique is suitable for stand-alone inverter due to its feasibility and has good performance to produce almost pure sinusoidal output waveform.

In a rooftop PV installation, shading problem caused by building layout and other obstacles such as trees and surrounding objects is commonly observed and potentially reduces the maximum power that can be harvested from the array. In such condition, among the solutions available is to group the shaded modules into separate strings with dedicated module level power electronics (MLPE) to maximize its performance. Each separated group can have its own power electronis device configuration and implementation of MPPT with different maximum power point voltage and current output. In this context, the use of cascaded H-bridge multilevel topology has an advantage of producing a higher sinusoidal output based on the several lower input voltages as proposed in this paper. No literature so far has discussed specifically on this area plus with the integration of energy storage element which is necessary for the standalone PV system. It thoroughly discusses the configuration and modelling process of the system including the design of the voltage and current controllers.

The rest of contents of the paper are structured as follow. In the next Section 2, the modelling and design of the stand-alone H-bridge MLI is presented. Section 3 discusses on the simulation conducted to verify the workability of the proposed design before the work is concluded in Section 4. 


\section{SYSTEM MODELLING AND DESIGN}

Figure 1 shows the configuration of a cascaded H-bridge inverter for stand-alone PV inverter system with energy storage. Each H-bridge unit has its own PV source with array of modules with specifications in Table 1 based on the commercial product of Sunpower SPR-225-series [23]. Due to shading problem, the modules in the array are sepated into two groups. The first array is configured in 4-parallel strings of 3-series connection with $V_{m p p}$ at $123 \mathrm{~V}$ and $I_{m p p}$ at 22 A to produce approximately $2700 \mathrm{~W}$ power at maximum irradiation. While the second array is in 3-parallel strings of 2-series connection with $V_{m p p}$ at $82 \mathrm{~V}$ and $I_{m p p}$ at 16.5 A to produce approximately $1350 \mathrm{~W}$. Combination of both configurations produces approximately $4 \mathrm{~kW}$ of power. The power curve corresponds to both configurations is shown in Figure 2(a) and (b).

A boost DC-DC converter before the inverter functions to increase the voltage at the DC link to 200 $\mathrm{V}$ as well as for maximum power point tracking (MPPT) implementation. With the output of the converter at the DC link regulated at costant value, the MPPT algorithm based on the Pertube and Observation (P\&O) method is used to vary the PV arrays terminal voltage according to the power curve of the two PV array configurations as shown in Figure 2(c). The voltage and current from the PV array are continuously sampled, where their product power $P$ is compared with the value from the previous sampling. Then decision is made whether to increase or decrease the voltage by regulating the duty cycle $d$ for switching the converter switch.

The output of the two H-bridges are cascaded in series to produce a larger 5-levels output voltage. An LC filter is used to mitigate the harmonics to produce a low harmonics sinusoidal waveform across the load. As for the energy storage unit, a lead acid battery is used and connected to the DC link capacitor of each inverter via the bidirectional DC-DC converter. The controller unit functions to control the sinusoidal output of the inverter, the DC link voltage and charging/discharging operation of the battery storage. Table 2 lists the related parameters of the system.

The bidirectional converter (BDC) consists of two switches, a capacitor and inductor. The two switches $S_{a}$ and $S_{b}$ are operated accordingly, enabling the converter to control the power flow bidirectionally in buck and boost mode. It discharges the battery in the forward mode (boost) during high load condition and recharges the battery pack in reverse mode (buck) when the load is in low demand and power is abundantly available from the PV source.

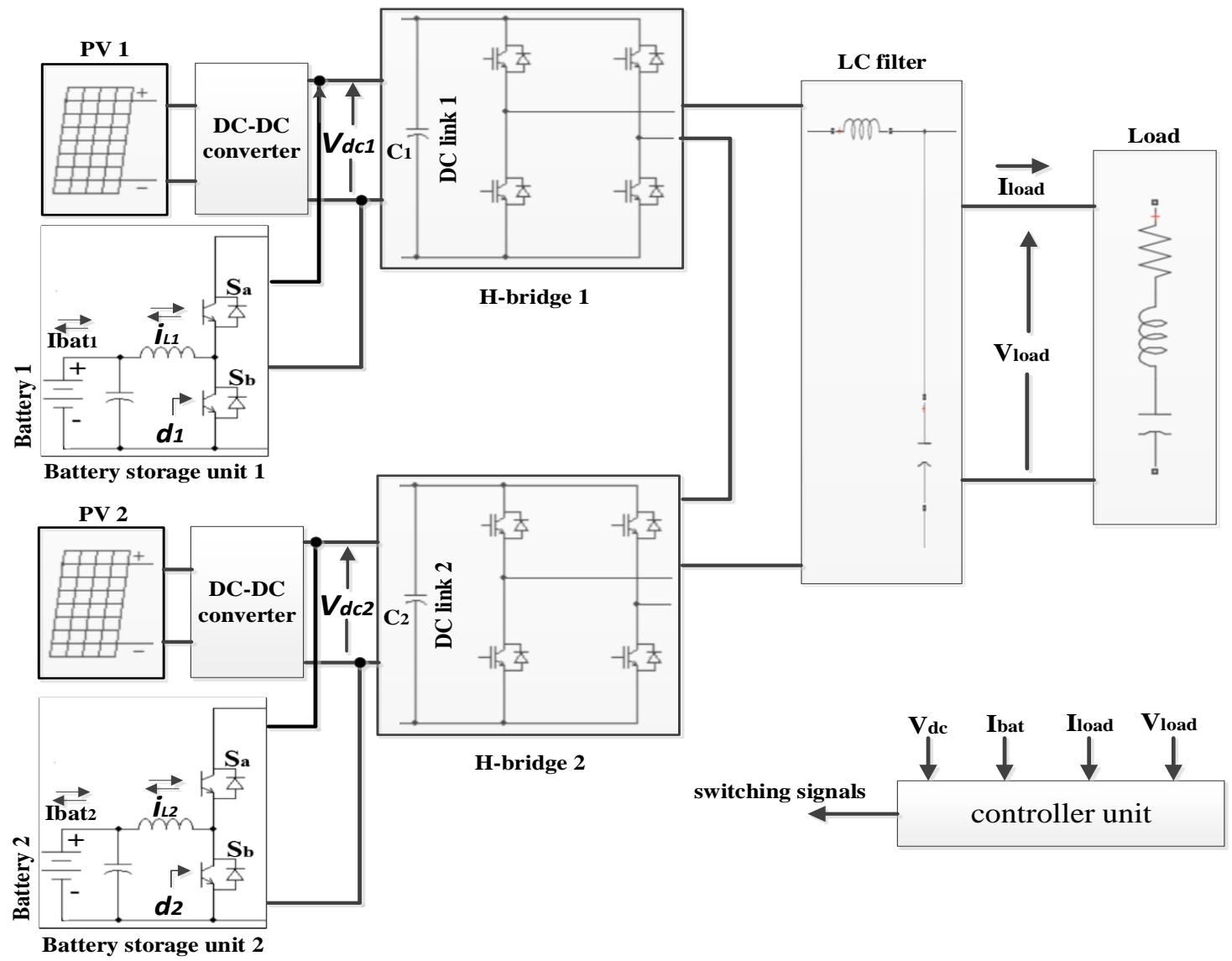

Figure 1. Configuration of cascaded H-bridge stand-alone PV inverter with energy storage 


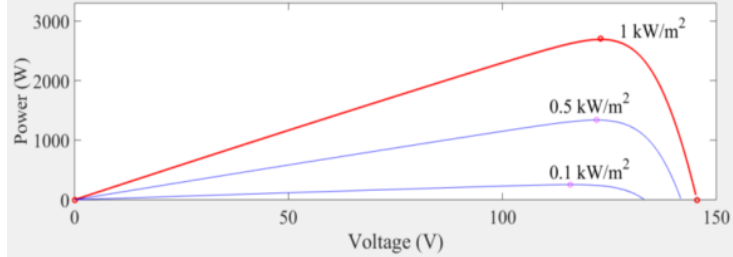

(a)

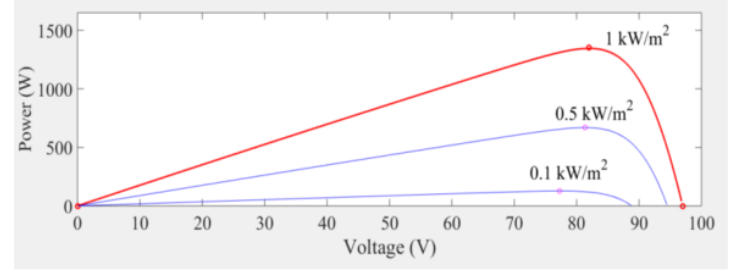

(b)

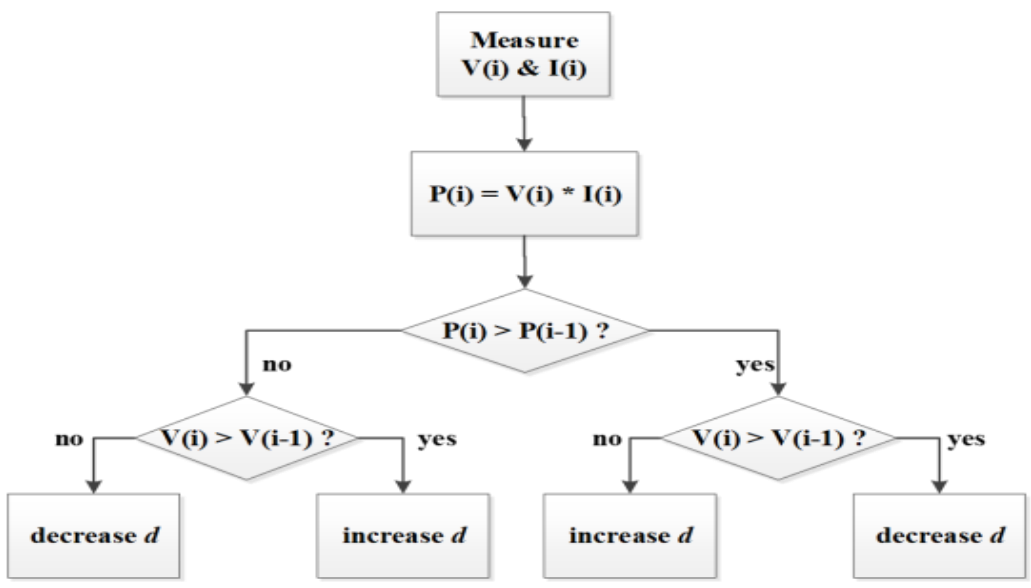

(c)

Figure 2. Power curve based on Sunpower SPR-225-series (a) 3x4 PV array configuration, (b) $2 \times 3$ PV array configuration and (c) P\&O algorithm for MPPT implementation

Table 1. Specifications of PV array configuration

\begin{tabular}{cccc}
\hline PV Array 1 & \multicolumn{3}{c}{ PV Array 2 } \\
\hline Parameters & Values & Parameters & Values \\
\hline Peak power, $P_{\max }(+/-5 \%)$ & $2700 \mathrm{~W}$ & Peak power, $P_{\max }(+/-5 \%)$ & $1350 \mathrm{~W}$ \\
Rated Voltage, $V_{m p p}$ & $123.0 \mathrm{~V}$ & Rated Voltage, $V_{m p p}$ & $82 \mathrm{~V}$ \\
Rated Current, $I_{m p p}$ & $22 \mathrm{~A}$ & Rated Current, $I_{m p p}$ & $16.5 \mathrm{~A}$ \\
Open Circuit Voltage, $V_{o c}$ & $145.5 \mathrm{~V}$ & Open Circuit Voltage, $V_{o c}$ & $97 \mathrm{~V}$ \\
Short Circuit Current, $I_{s c}$ & $23.5 \mathrm{~A}$ & Short Circuit Current, $I_{s c}$ & $17.61 \mathrm{~A}$ \\
\hline
\end{tabular}

Table 2. Parameters of the circuit configuration for the five-level cascaded H-bridge inverter

\begin{tabular}{cccc}
\hline Parameters & Values & Parameters & Values \\
\hline PV power, $P_{p v}$ & $4 \mathrm{~kW}$ & Battery storage (at nominal) & $96 \mathrm{~V}, 42 \mathrm{Ah}$ \\
DC link voltage, $V_{d c}$ & $200 \mathrm{~V}$ & bidirectional converter $C, L$ & $260 \mathrm{uF}, 1.25 \mathrm{mH}$ \\
Switching frequency, $f_{\mathrm{sw}}$ & $10 \mathrm{kHz}$ & Filter inductor, $L_{f}$ & $6.7 \mathrm{mH}$ \\
Load voltage, $V_{p k}$ & $339.6 \mathrm{~V}$ & Filter capacitor, $C_{f}$ & $2.8 \mathrm{uF}$ \\
maximum inverter output load & $4 \mathrm{~kW}$ & & \\
\hline
\end{tabular}

\subsection{DC link voltage control}

For a proper operation of the inverter, the voltage of the DC link $V_{C 1}$ and $V_{C 2}$ at each H-bridge inverter must be controlled at a constant value. For that, a dual loop control strategy for the bidirectional converter with the current and voltage controller as discussed in [20] is applied as shown in Figure 3. At the outer loop, the voltage controller is used to control the DC link voltage $\left(V_{d c l}\right.$ and $\left.V_{d c 2}\right)$. The PI controller generates the reference current $I_{\text {ref }}{ }^{*}$ for controlling the inductor current $I_{L}$ in the inner loop. With the voltage output at the DC link is designed to maintain at $200 \mathrm{~V}$, the inverter output able to achieve $240 \mathrm{~V}_{\text {rms }}$ output across the load. The $I_{\text {ref }}$ is the reference current for the current controller. In boost mode, the inductor current is controlled to discharge the battery current, while in the buck mode it is controlled to recharge the battery. The proportional gain, $k_{p}$ and integral gain, $k_{i}$ for both controllers are designed based on the derived transfer function of voltage-to-inductor current and inductor current-to-duty ratio as in [24]-[25]. By using PID Tuner Apps in Matlab Simulink, the bode plot frequency response analysis is conducted to verify the stability of the designed controllers as shown in Figure 4. 

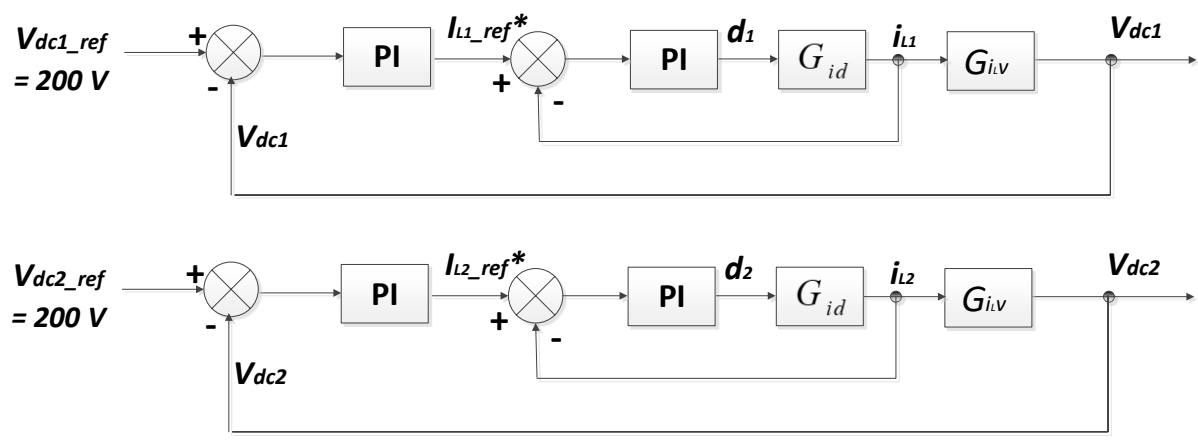

Figure 3. Dual loop control strategy for the bidirectional converter with current and voltage controller

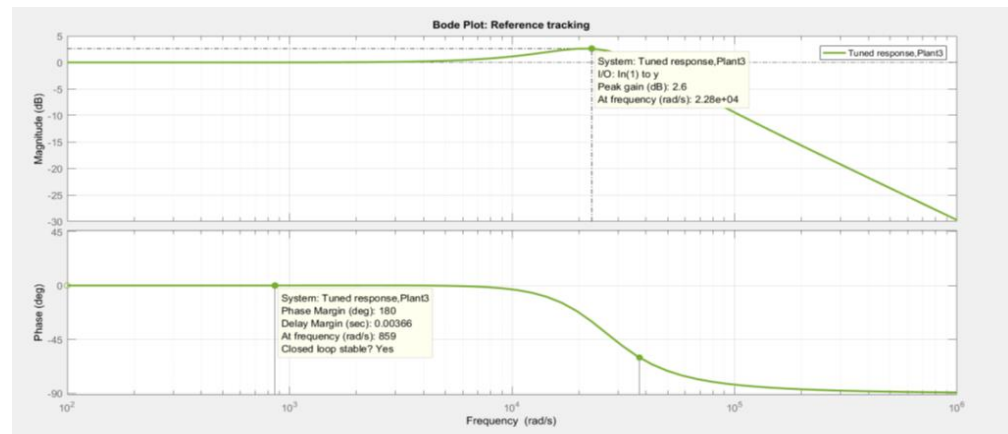

(a)

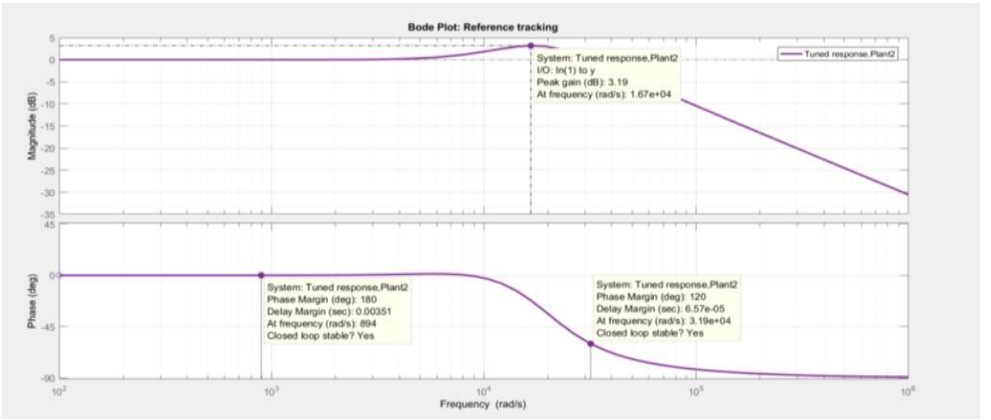

(b)

Figure 4. The closed loop bode plot frequency analysis for (a) voltage controllerand, (b) current controller in PID Tuner Apps

\subsection{Inverter output voltage control}

Figure 5 shows the circuit configuration of the single-phase H-bridge inverter with the second order LC filter $\left(L_{f}, C_{f}\right)$ and a resistive load $R_{\text {load }}$. Based on the circuit, the differential equations can be derived as in (1) to (4).

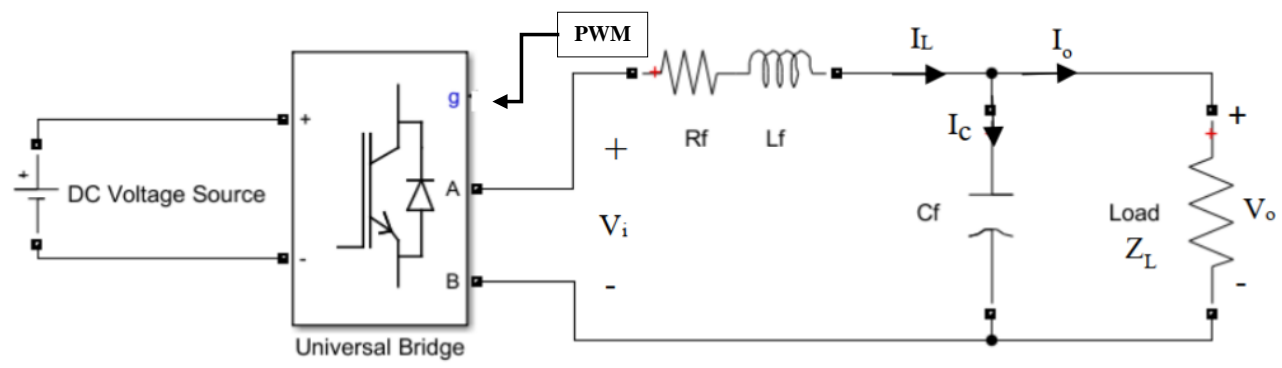

Figure 5. Configuration of single-phase H-bridge inverter 


$$
\begin{aligned}
& V_{i}(s)=R_{f} i_{l}(s)+L_{f} i_{l}(s)+V_{o}(s) \\
& i_{c}(s)=i_{l}(s)-i_{o}(s) \\
& V_{o}(s)=\frac{1}{C_{f} s} i_{c}(s) \\
& i_{o}(s)=\frac{V_{o}}{Z_{L}}
\end{aligned}
$$

Based on the circuit and the equations, the linear model of the H-bridge inverter shown in Figure 6 can be obtained [26]. $V_{d c}$ is the DC input voltage, $V_{t r i}$ is the peak voltage of the triangular carrier wave, $V_{i}$ is the inverter $\mathrm{AC}$ output voltage, $V_{o}$ is the output load voltage, $i_{L}$ is the inductor current, $i_{c}$ is the capacitor current, $i_{o}$ is the load current, $R_{f}$ is the filter resistance, $L_{f}$ is the filter inductance, $C_{f}$ is the filter capacitance and $Z_{L}$ is the resistive load.

The control circuit for controlling the output voltage across the load uses two feedback loops; the inner current loop which increases the speed response of the controller and reduces the total harmonic distortion of the output $\mathrm{AC}$ voltage, and the second loop is the outer voltage loop, which has a slow response but regulates the output AC voltage. The transfer functions for the inner current controller and outer voltage controller can be derived by referring to the (1) to (4). An approximate linear model of the single-phase multilevel H-bridge inverter with the current and voltage controller is constructed as shown in Figure 7. In the Matlab environment, the control circuit is constructed as shown in Figure 8. The inner current feedback loop is connected in series to the capacitor current measurement and the outer voltage feedback loop is connected in parallel to the output load voltage measurement.

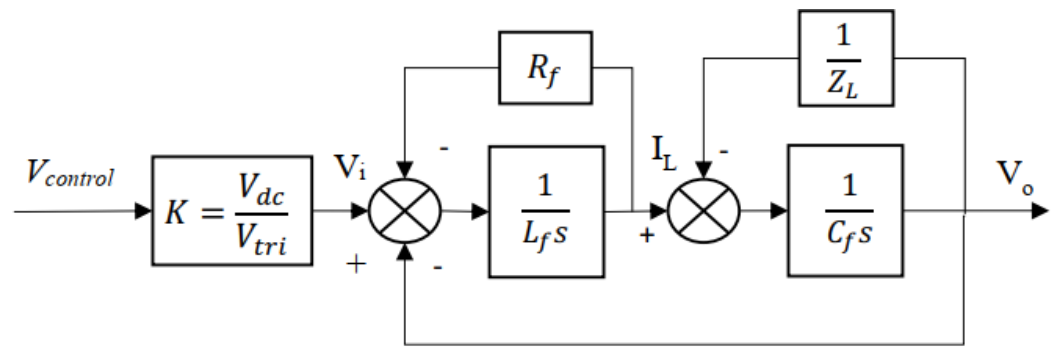

Figure 6. Linear model based on the H-bridge inverter in Figure 5

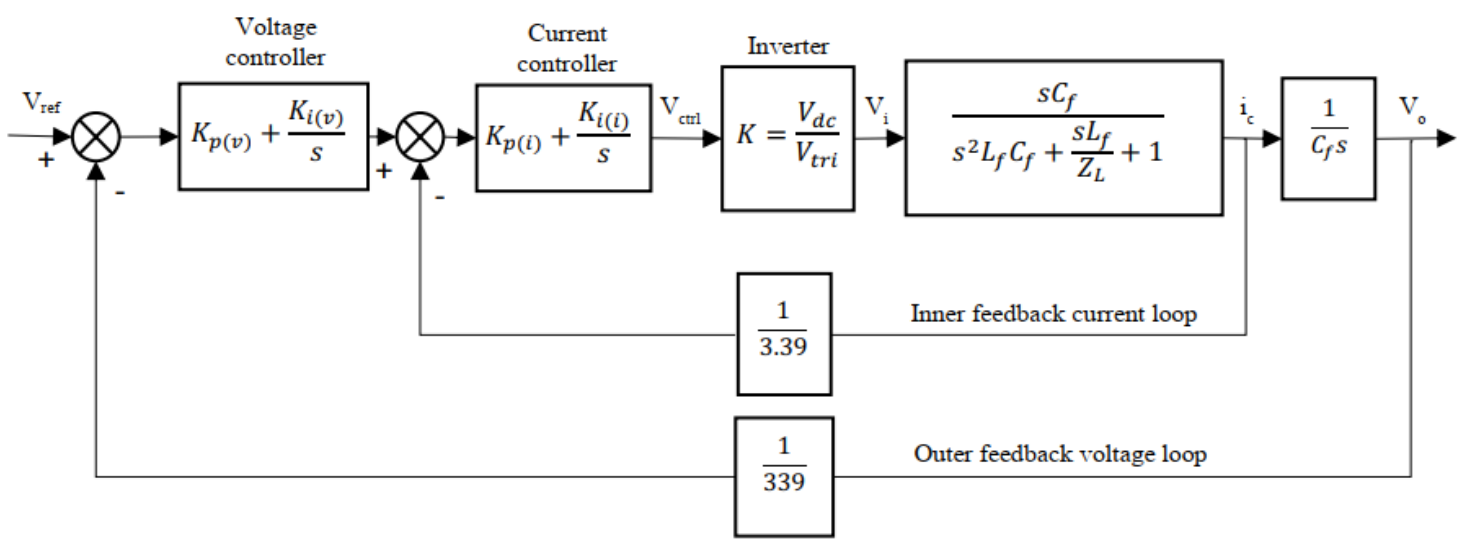

Figure 7. The linear model of the H-bridge inverter with current and voltage controller 


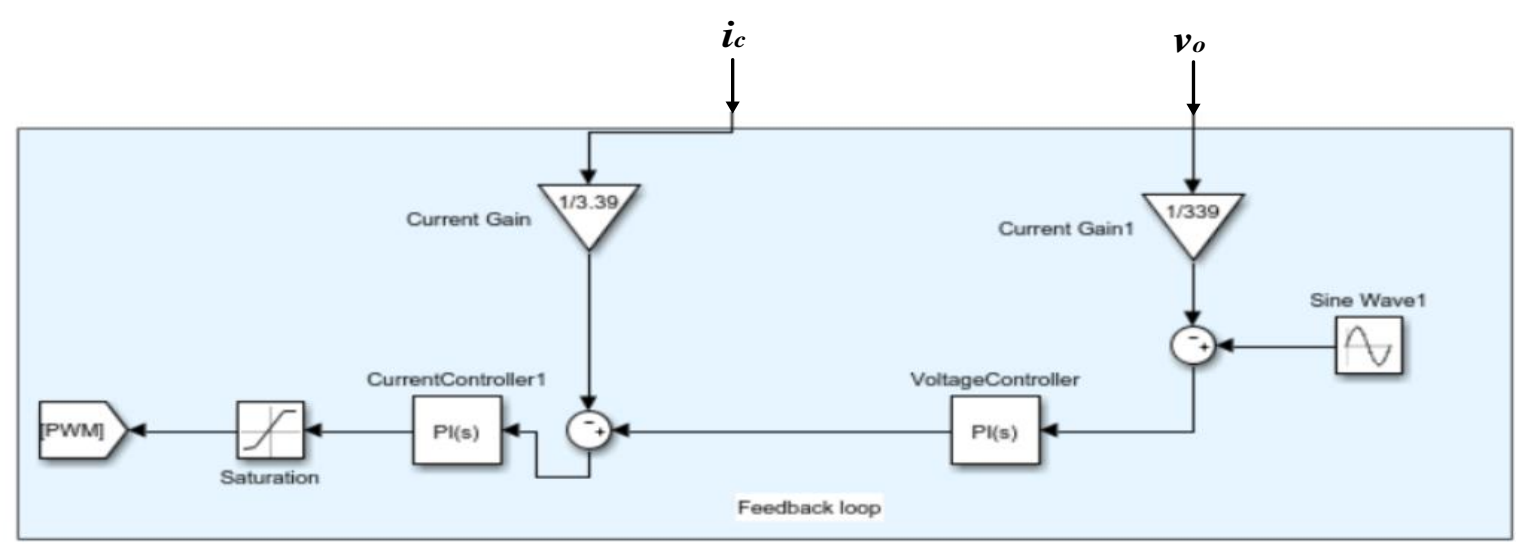

Figure 8. Construction of multi-feedback loop for the H-bridge inverter current and voltage controller in Matlab environment

\section{SIMULATION RESULTS}

Verification of the proposed design of the cascaded H-bridge inverter with energy storage is conducted using the Matlab Simulink software. A typical scenario of solar insolation and daily residential household power consumption as shown in Figure 9 is created as a reference for the simulation. The solar insolation is basically low in the morning and as the sun comes out and climbing higher, the insolation is gradually increasing and reach the maximum point at noon. Then it gradually decreasing as the sun going down until the sunset. On the power consumption, the load is minimum between $10.00 \mathrm{pm}$ to 5.00 am, and high in the morning when the daily routines start between 7.00 to $9.00 \mathrm{am}$, as well as between $5.00 \mathrm{pm}$ to $8.00 \mathrm{pm}$ when everybody is back at home. A moderate power consumption is expected when minimum people are at home between 9.00 am to $3.00 \mathrm{pm}$. Due to computation burden constraint, the simulation time is normalized to 21 seconds to represent the 17 hours consumption behaviour in Figure 9.

Figure 10 shows part of the results that firstly shows that the overall system according as expected. Looking at the generated PV power $P_{p v}$ in top-left figure, both groups of arrays achieved approximately 2700 $\mathrm{W}$ and $1350 \mathrm{~W}$ power at maximum irradiation. In the bottom-left figure, the DC link voltage at both input of the inverter terminal is well controlled at $200 \mathrm{~V}$. The top-right figure shows the inverter output voltage before the filter which is at $400 \mathrm{~V}_{\mathrm{p}-\mathrm{p}}$ and lastly the zoom-in waveforms of voltage and current (15 times magnified) at the load side after the filter at the bottom-right figure. The successful control of the DC link voltage guarantees the output voltage to be stable at $240 \mathrm{Vrms}$

Figure 11 shows the results on the power management between the PV arrays, battery storage units and the loads. The top-lef figure shows the discharged and recharged current of both batteries, the bottom-left figure shows the amount of power discharge/recharged from/into the batteries $P_{b a t}$, the top-right figure shows the relation between the total power output of the inverter $P_{i n v}$ with the power consumed at the load $P_{\text {load }}$ and lastly the bottom-right figure shows the state of charge $(\mathrm{SoC})$ of both batteries over the simulation. Between 0 to 4s when the $P_{p v}$ is lower than $P_{\text {load }}$, the difference is compensated by $P_{b a t}$ which is the amount of power discharged by the battery. Then gradually the $P_{p v}$ increases and surpass the load demand and extra power flows to recharge the battery between 4 to $15 \mathrm{~s}$. After $15 \mathrm{~s}$ of simulation, $P_{l o a d}$ exceeds the $P_{p v}$ and as a result, the batteries start to discharge again up to $3 \mathrm{~kW}$ of power at maximum. From the top-right figure, it can be seen the total output power $P_{i n v}$ always matches with the consumed power $P_{\text {load }}$ at the load side. From the SoC curves in the bottom-right figure, as expected they are proportional with the battery current curves in the bottom-left figure where battery 1 is charged more compared to battery 2 based on the higher charging current. In overall it shows a balance power transfer between the PV sources, load and the battery storage units.

The top-left figure of Figure 11 also proves the satisfactorily working current control by the bidirectional DC-DC converter. The $I_{b a t}$ tracks the reference current $I_{\text {ref }}^{*}$ satisfactorily to discharges and recharges the right amount of power from/into the battery. Positive value indicates the current is flowing out from the battery and negative values indicates the current flows into the battery. Both batteries' currents are controlled to discharge at approximately between 2 to 8 A when the $P_{p v}$ is low between 0 to $4 \mathrm{~s}$, and between 4 to $15 \mathrm{~s}$, they are controlled to recharge the battery and reach a maximum value of $18 \mathrm{~A}$ when the $P_{p v}$ reach its maximum of $4 \mathrm{~kW}$. As the $P_{\text {load }}$ starts to increase from $15 \mathrm{~s}$ and $P_{p v}$ is gradually decreasing, the $I_{b a t}$ is controlled to discharge and achieve a maximum value of $15 \mathrm{~A}$ at $19 \mathrm{~s}$. The results verify that the control of the inductor current works according to the requirement by the BDC. With the successful control of the inductor current, the dual loop voltage control for the DC link voltage is also verified as shown in Figure 10 (bottom-left). On the 
inverter AC side, the output voltage controller successfully maintains the output across the load at $240 \mathrm{Vrms}$ $\left(339.6 \mathrm{~V}_{\mathrm{pk}}\right.$ ) as the load current is varied throughout the simulation as shown in Figure 12. This is also contributed by the constantly controlled value of $200 \mathrm{~V}$ DC link voltage at the inverter input.

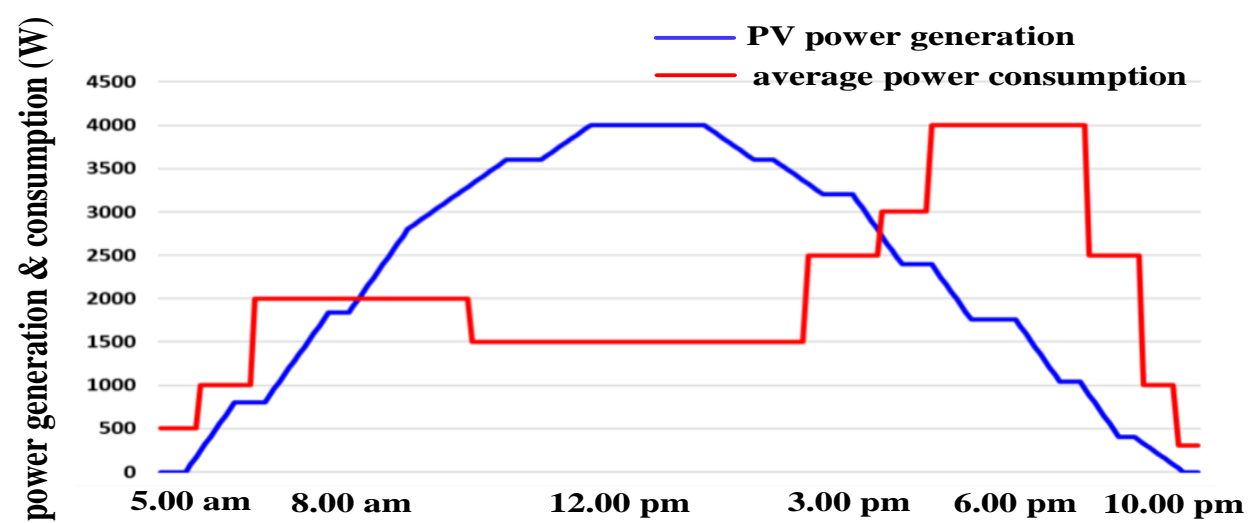

Figure 9. Typical daily PV power generation curve and the residential household power consumption
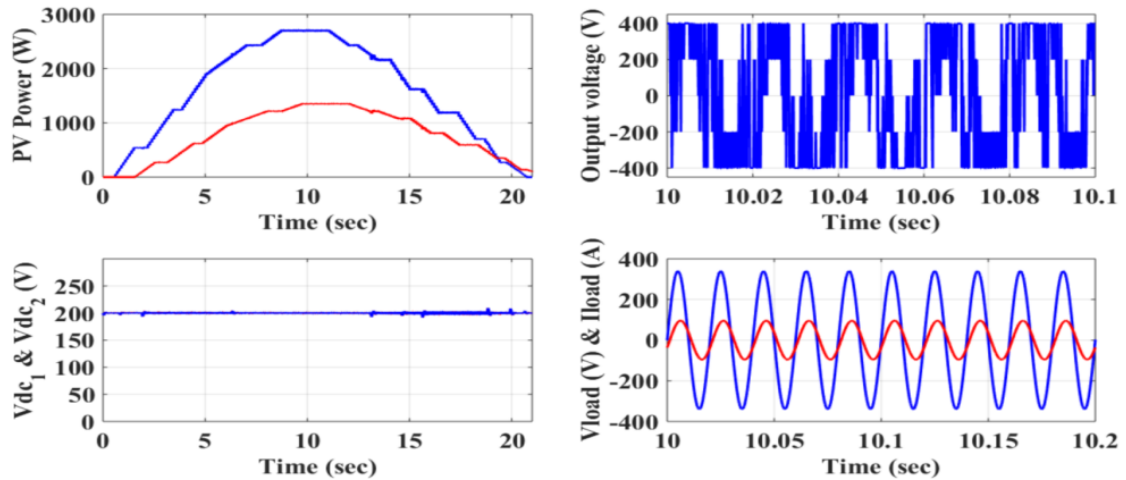

Figure 10. PV power generated by both groups of arrays (top-left), DC link voltage across the inverter terminal (bottom-left), zoom-in waveform inverter output voltage before the filter (top-right) and zoom-in voltage and current (15 times magnified) at the load (bottom-right)
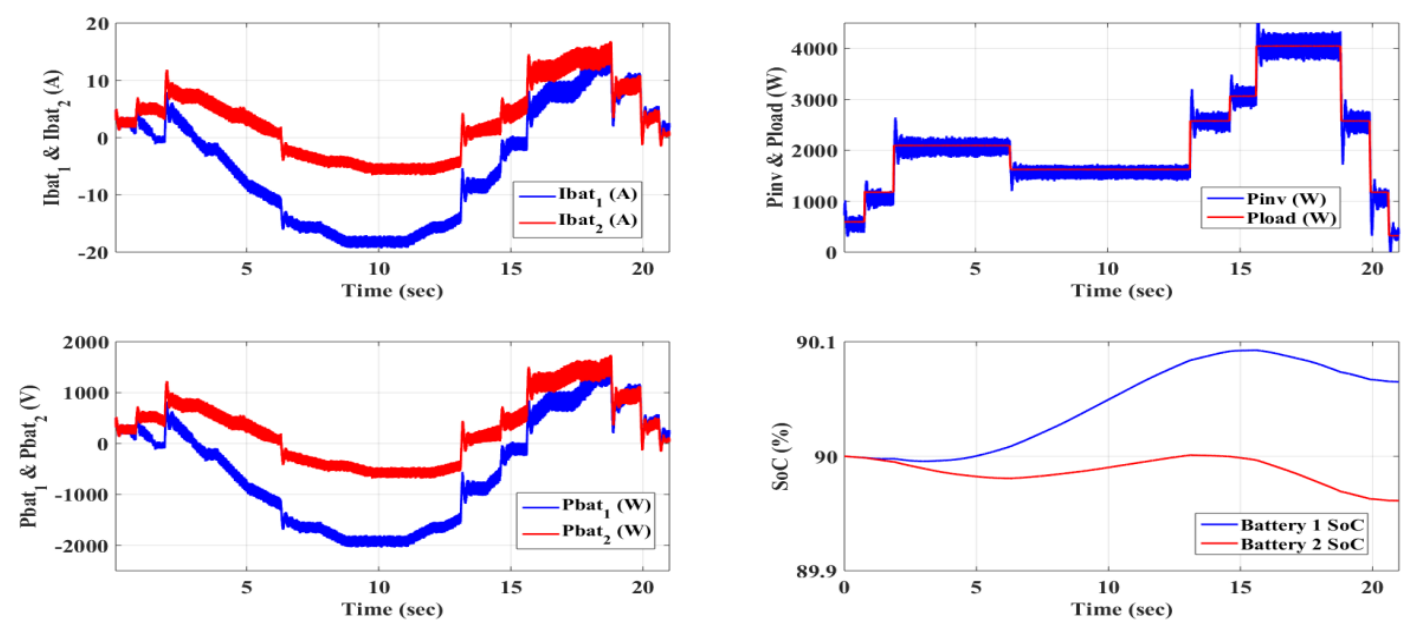

Figure 11. Discharged and recharged current of battery $1\left(I_{b a t 1}\right)$ and battery $2\left(I_{b a t 2}\right)$ (top-left), power discharge/recharged from/into the batteries $P_{b a t}$ (bottom-left), relation between the total power output of the inverter $P_{i n v}$ with the power consumed at the load $P_{l o a d}$ (top-right) and SoC of battery 1 and battery 2 over the simulation (bottom-right) 

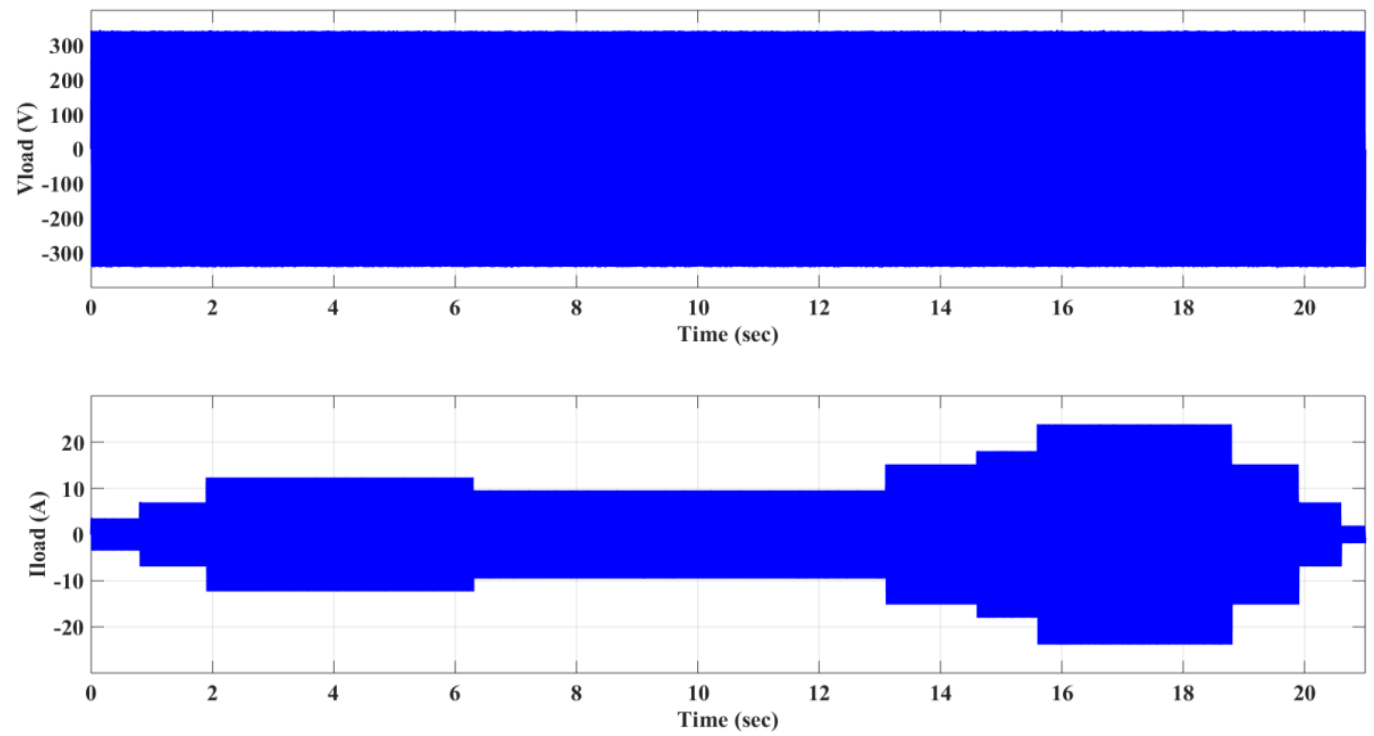

Figure 12. Voltage $V_{\text {load }}$ (top) and current $I_{\text {load }}$ at the load side

\section{CONCLUSION}

In this work, the design of cascaded H-bridge inverter for stand-alone PV system with energy storage is proposed. The bidirectional DC-DC converter is used for realizing a bidirectional power flow between the battery energy storage and the inverter with the dual-loop voltage and current control. At the inverter AC side, the multiple feedback loop control is applied for controlling the output voltage. Based on the simulation results under Matlab Simulink environment, the proposed design works accordingly to satisfactorily manage the power flow between the PV source, load side and the energy storage. By connecting the H-bridge units in cascaded configuration, a higher output voltage with good harmonics performance can be achieved thus compensating the constraint of low voltage at the inverter input such as in PV application.

\section{ACKNOWLEDGEMENTS}

The authors would like to acknowledge the funding support provided by the Universiti Teknikal Malaysia Melaka (UTeM) and the Ministry of Higher Education Malaysia under the research grant No: RACER/2019/FKE-CERIA/F00398.

\section{REFERENCES}

[1] Kavitha, M., Elanangai, V., Jayaprakash, S. and Balasubramanian, V., "Development of regenerative braking concept for electric vehicle enhanced with bidirectional converter," International Journal of Power Electronics and Drive Systems, vol. 9, no. 4, pp. 1584-1590, 2018, doi: 10.11591/ijpeds.v9.i4.pp1584-1590

[2] Punna, S., Manthati, U. B. and Chirayarukil Raveendran, A., "Modeling, analysis, and design of novel control scheme for two-input bidirectional DC-DC converter for HESS in DC microgrid applications," International Transactions on Electrical Energy Systems, p. e12774, 2021, doi: 10.1002/2050-7038.12774.

[3] Dominic Savio, A. and Vimala Juliet, A., "Development of multiple plug-in electric vehicle mobile charging station using bidirectional converter," International Journal of Power Electronics and Drive Systems, vol. 11, no. 2, pp. 785-791, 2020, doi: 10.11591/ijpeds.v11.i2.pp785-791.

[4] Thumma, R., Bhajana, V. V. S. K. and Aylapogu, P. K., "Design and simulation of a new ZVT bi-directional DCDC converter for electric vehicles," Indonesian Journal of Electrical Engineering and Computer Science, vol. 7, no. 1, pp. 75-83, 2017, doi: 10.11591/ijeecs.v7.i1.pp75-83.

[5] Miao, T., Liu, X., Liu, S. \& Wang, L. 2021, "A new control strategy for Bi-directional DC/DC converter in DC microgrid", E3S Web of Conferences, 2021, vol. 233. EDP Sciences, doi: 10.1051/e3sconf/202123301051.

[6] Ranipriya, G., Jegathesan, R. and Vijayakumar, K., "An integrated four port bidirectional dc-dc converter for photovoltaic energy harvesting systems," IEICE Electronics Express, vol. 16, no. 23, 2019, doi: 10.1587/elex.16.20190495.

[7] Lopez-Garcia, T. B., Sanchez, E. N. and Ruiz-Cruz, R., "Real-time implementation of battery bank chargedischarge based on neural inverse optimal control," IET Renewable Power Generation, vol. 13, no. 16, pp. 31243132, 2019, doi: 10.1049/iet-rpg.2019.0581. 
[8] Bhagiya R. D. and Patel R. M., "PWM based Double loop PI Control of a Bidirectional DC-DC Converter in a Standalone PV/Battery DC Power System," 2019 IEEE 16th India Council International Conference (INDICON), Rajkot, India, 2019, pp. 1-4, doi: 10.1109/INDICON47234.2019.9028974.

[9] Satya Sai Chandra M. V., Kumar B. D. B, L. V. and Mohapatro S., "Voltage Control and Energy Management of Solar PV fed Stand-alone Low Voltage DC Microgrid for Rural Electrification," $21^{\text {st }}$ National Power Systems Conference (NPSC), pp. 1-6, 2020, doi: 10.1109/NPSC49263.2020.9331911.

[10] Al-Soeidat M., Khawaldeh H., Lu D. D. and Zhu J., "A Novel High Step-up Three-Port Bidirectional DC/DC Converter for PV-Battery Integrated System," IEEE Applied Power Electronics Conference and Exposition (APEC), 2020, pp. 3352-3357, doi: 10.1109/APEC39645.2020.9124295.

[11] Chandekar A., Saonerkar A. K. and Naik S. D., "Design of Isolated Bi-Directional Converter for PV System," 2018 Second International Conference on Inventive Communication and Computational Technologies (ICICCT), pp. 1248-1251, 2018, doi: 10.1109/ICICCT.2018.8473090.

[12] Gorji, S. A., Sahebi, H. G., Ektesabi, M. and Rad, A. B., "Topologies and control schemes of bidirectional DC-DC power converters: An overview," IEEE Access, vol. 7, pp. 117997-118019, 2019, doi: 10.1109/ACCESS.2019.2937239.

[13] Rasheed, M., Omar, R., Sulaiman, M. and Abd Halim, W., "A modified cascaded h-bridge multilevel inverter based on particle swarm optimisation (PSO) technique," Indonesian Journal of Electrical Engineering and Computer Science, vol. 16, no. 1, pp. 41-45, 2019, doi: 10.11591/ijeecs.v16.i1.pp41-51.

[14] Babaei, E., Laali, S. and Bayat, Z., "A single-phase cascaded multilevel inverter based on a new basic unit with reduced number of power switches," IEEE Transactions on industrial electronics, vol. 62, no. 2, pp. 922-929, 2014.

[15] Rasheed, R., Saju, K.K. and Bindu, V., "A five-level multilevel topology utilizing multicarrier modulation technique," International Journal of Power Electronics and Drive Systems, vol. 10, no. 2, pp. 868-873, 2019, doi: 10.11591/ijpeds.v10.i2.pp868-873.

[16] Lee, E. J., Kim, S. M. and Lee, K. B., "Modified phase-shifted PWM scheme for reliability improvement in cascaded H-bridge multilevel inverters," IEEE Access, vol. 8, pp. 78130-78139, 2020, doi: 10.1109/ACCESS.2020.2989694.

[17] Tan, R. H. G., Chuin, C. B. and Solanki, S. G., "Modeling of single phase off-grid inverter for small standalone system applications," International Journal of Power Electronics and Drive Systems, vol. 11, no. 3, pp. 1398-1405, 2020, doi: 10.11591/ijpeds.v11.i3.pp1398-1405.

[18] Leong, T. T. and Ishak, D., "Deadbeat-based PI controller for stand-alone single-phase voltage source inverter using battery cell as primary sources," 2011 IEEE Conference on Clean Energy and Technology (CET), 2011, pp. 87-92, doi: 10.1109/CET.2011.6041442.

[19] Tahir, S., Wang, J., Baloch, M. H. and Kaloi, G. S., "Digital control techniques based on voltage source inverters in renewable energy applications: A review," Electronics, vol. 7, no. 2, p. 18, 2018, doi: 10.3390/electronics7020018.

[20] Algaddafi, A., "Stand-alone Inverter: Reviews, Models and Tests the exist system in Term of the Power Quality, and Suggestions to Design it," Advances in Science, Technology and Engineering Systems Journal, vol. 1, pp. 3441, 2016, doi: 10.25046/aj010507.

[21] Ryan, M. J. and Lorenz, R. D., "A high performance sine wave inverter controller with capacitor current feedback and "back-EMF" decoupling," PESC Record - IEEE Annual Power Electronics Specialists Conference, 1995, pp. 507, doi: 10.1109/PESC.1995.474857.

[22] Sunpower 225 Solar Panel, Accessed on $30^{\text {th }}$ Jun 2021, [online], available: https://www.energymatters.com.au/images/sunpower/SPR-225_com.pdf

[23] Mohamed S. Zaky, "Design of Multiple Feedback Control Loops for a Single-phase Full-bridge Inverter Based on Stability Considerations," Electric Power Components and Systems, vol. 43, no. 20, pp. 2325-2340, 2015. doi: $10.1080 / 15325008.2015 .1082164$.

[24] Junhong Zhang, Jih-Sheng Lai and Wensong Yu, "Bidirectional DC-DC converter modeling and unified controller with digital implementation," 2008 Twenty-Third Annual IEEE Applied Power Electronics Conference and Exposition, Austin, TX, USA, 2008, pp. 1747-1753, doi: 10.1109/APEC.2008.

[25] Jia X., Hu C., Du S., Chen M., Lin P. and Xu D., "DC-link voltage control strategy of a bi-directional DC/DC converter for electric vehicles," 2015 IEEE Energy Conversion Congress and Exposition (ECCE), Montreal, QC, Canada, 2015, pp. 92-99, 2015, doi: 10.1109/ECCE.2015.

[26] Mansoor, K. Z. and Abdullah, G. A., "Analysis and simulation of singlephase inverter controlled by neural network,” Al-Rafidain Engineering Journal (AREJ), vol. 20, no. 6, pp. 1-14, 2012. 